\title{
Drug Induced Cancers: Simultaneously Development of Cutaneous Melanoma, Colon Carcinoma and Kaposi Sarcoma under Valsartan/ Hydrochlorothiazide
}

\author{
Georgi Tchernev*, Gavrail Poterov
}

Onkoderma-Clinic for Dermatology, Venereology and Dermatologic Surgery, General Skobelev, Sofia, Bulgaria

Received: November 01, 2020; Accepted: November 05, 2020; Published: November 06, 2020

*Corresponding author: Professor Georgi Tchernev, PhD, Onkoderma-Clinic for Dermatology, Venereology and Dermatologic Surgery, Sofia, Bulgaria, Tel. No:00359885588424; E-mail: georgi_tchernev@yahoo.de

\section{Abstract}

The side effects of antihypertensive drugs are often the subject of discussions, publications and presentations, but not in cases where they include in their "palette" or "repertoire" concepts such as generating / promoting or potentiating various types of cancer, as well as metastasis of already existing one.

Unfortunately, progress within the real, clinical medicine often does not start with the desired results (from those expected within clinical observations or experimental data after administration of a particular substance or drug). Breakthroughs in medicine and progress start with the careful registration and analysis of unwanted and unexpected, unplanned results. Again, unfortunately, the analysis of it is often swept under the table, without thinking that the negative results should be the generator of progress. When the observations of certain clinical or experimental data remain insufficiently analyzed, neglected or deliberately hidden - the result is often alarming or fatal - similar to the scandals (from 2018) with Sartans and the generation of hundreds of cutaneous melanomas, as well as heterogeneous species and other cancerous forms. However, if we all focus together on the problems through the prism of the possibilities to solve them, there is a real chance to achieve a drastic decrease in the incidence of a number of tumor diseases, due to the possibility of rethinking their pathogenesis. The article is a kind of analysis and directing clinicians in the right direction in relation to an urgent need to clarify issues related to the procarcinogenic effect of drugs from the so-called group of Sartans and Thiazide diuretics. In the first mentioned drugs, the carcinogenic effect could be due to: 1) the action of the main substance of the Sartans themselves (proven in experimental conditions, but also in in vivo data) and 2) the additive, undesirable ingredients or the so-called nitrosamines arising as additional contamination within the production process. The combination of Sartans and Thiazide diuretics (plus Nitrosamines, the presence of which is not adequately tested) could in all likelihood have a fatal, mutually potentiating procarcinogenic effect, leading to the manifestation of 3 or even more cancers simultaneously. This publication presents for the first time in the world literature a patient who developed three cancers at the same time (Kaposi's sarcoma, skin melanoma and colon cancer) after starting therapy with Valsartan and hydrochlorothiazide.

Our critical analysis is focused on the regulatory authorities in the face of the FDA, EMA, but also on the National Agency for Drug Control. Attention is also paid to the non-traditional and illegal from the point of view of all ethical norms ways of influencing the pharmaceutical industry, in order to protect its positions in the framework of the daily emerging world scandals.
\end{abstract}

Keywords: Valsartan, Hydrochlorothiazide; Cutaneous Melanoma; Colon Carcinoma; Kaposi Sarcoma; Drug Induced Cancer; FDA; Novartis; EMA

\section{Introduction}

The Sartan-Problem, The Ambivalent behavior of FDA and the unanswered questions?

Antihypertensive medication, and in particular the Sartans, have been associated in the scientific literature since 2010 with a "modestly high incidence" of all types of cancer, and according to some authors - this "modest risk" could be defined to some extent as problematic [1]. About a year later, following the alarming publication in the Lancet Oncology, there was a refutation of these alarming scientific data from the FDA itself, and this refutation was updated several times in the years: last in 2017 and is visible even today on the FDA website [2]. In fact, 8 years later, in 2018 (or after scientists found an increased risk of developing certain cancers (after taking Sartans in 2010), the FDA itself was the one to warn not about the modestly increased risk of cancer forms in patients, and what about the presence of up to 3 carcinogens that cause up to 11 forms of cancer and are contained in tablets, which are defined as SARTANS? The question remains: "Who is responsible for the" modest-risk "(according to scientific data / Lancet Oncology 2010) or" absolutely risk-free "according to the FDA, cancer forms within the intake of Sartans for the period 2010-2018? And why since drugs are "risk-free" (according to the FDA), did they had to be withdrawn from the market in the short term? Are the control in the face of the FDA / EMA available precisely to determine the risk after shared scientific data in top renowned medical journals such as Lancet Oncology, but also dozens of others, e.g. and react? On the basis of what data and what information does the FDA turn its opinion 180 degrees years later and for the benefit of whom?

Practically, it turns out that the actions of the control are in full 
synchrony with the data announced in 2010 in the scientific literature [1] with a slight delay of 8 years unlike their official statements in the press at the moment?

For example: “Don't worry! Keep taking your medication! There is no risk of cancer! "Medicines are being quietly withdrawn from the market, they contain carcinogens, but should they continue to be taken because there is practically no risk of developing cancer? Well, as there is no such risk - the reasonable question remains: "Why do you withdraw them and why have you delayed it for 8 years? Who benefited from this?"

The control authorities explain that the carcinogenic effect or the 'modest carcinogenic, at the same time scientifically justified risk' is due to the presence of nitrosamines (as possible contaminants) arising in the course of the production process in third countries [3]. As mentioned, it happens within a decade and remains dormant or undisclosed by the same controls - FDA / EMA? Despite the alarming data from 2010 (1)? And whether the delay in formalizing some of the real causes of potentiating cancer drugs is due to the fact that: the turnover of one of the drugs of a multibillion-dollar pharmaceutical company on the world market in 2019 is in the order of 2 billion dollars - remains just guessing? It remains unclear, but only for believers. This company roughly should have over 20 billion turnover of this drug in the last 10 years. And this drug is not the only Sartan that it offers on the world market.

\section{The hidden Truth: How to proceed?}

Until some time ago, it was not reported in any of the publications in the scientific literature that the carcinogenic effect of the sartans is due to impurities in the form of nitrosamines [1]. Scientific teams and clinicians define the drug sartan and do not exclude carcinogenic impurities in the form of nitrosamines from the general term "SARTAN" or the pill we swallow [1]. That is why our research team paid special attention to these two trends in 2018, which are still not analyzed objectively:

(1) possible carcinogenic effect of the active ingredient

(2) possible carcinogenic effect of the additional substances available in the drug: nitrosamines or others

(3) To our great disappointment, both the active ingredient and the drug impurities have a potential or potential carcinogenic effect.

\section{FDA, EMA and Governments over the World in favour of the pharmaceutical Industry?}

Contradictions in the answers over the years, but also in the approach of the Drug Control Agency itself (could be defined according to the opinion of a number of health experts around the world) and those with a strongly lobbyist-protectionist character. Or, as Erich Maria Remarque mentioned: "Nothing new on the Western Front!"

On one hand, there was no risk of developing cancers, and on the other hand, huge quantities of drugs should be withdrawn from the drug sector as soon as possible because they cause up to 11 forms of cancer? But be quiet. Make no noise. Let's go even further: After the thousands of patients' claims against pharmaceutical companies, due to "modestly high-risk cancers" that have arisen after taking sartans, there is no doubt or need to answer the question:

\section{"Who is protected by the FDA, and what is of interest?"}

Another type of antihypertensive drug, such as thiazide diuretics, is also associated with a "significantly increased risk" of developing non-melanocyte skin tumors [4], but probably also of cutaneous melanoma [5-8]. The most worrying aspect of the shared issue is the behavior of the regional drug control agencies in the respective countries: In a number of countries there is complete neglect regarding the official registration, analysis and formalization of cancer cases arising after the use of sartans and other antihypertensive drugs such as thiazide diuretics. The additional lack of freedom of the media and speech in EU countries, for example, the lack of patient information, the lack of prevention programs for patients taking this drug, certainly do not help reduce the number of cancers in general. On the contrary there is a pleasing complexity of the status quo in favor of rich pharmaceutical companies.

The formalization of scientific data and their relationship to the drug policy of control bodies, pharmaceutical companies and government, their behavior and the links between the abovementioned units, they are able to shed some light on the dilemma: "Do we want to get cancer and who is interested from this? Why is he hiding and from whom?"

The synchronous suppression of official data on the development of cancer forms after taking certain medications is also related to the "mandatory synchronous enrichment" of these same units.

We present a Bulgarian patient who took sartans in combination with hydrochlorothiazide, who developed three cancers simultaneously. The role of the mentioned drugs such as sartans and thiazide diuretics as possible carcinogenic triggers is discussed.

\section{Case report section}

We present a 74-year-old patient with complaints dating for 2 years. Concomitant diseases are known: arterial hypertension and hypertensive heart, without evidence of congestive heart failure. At the time of the examination was with data for atrial fibrillation and flutter. Systemic medication for the patient includes the following medications: From 2011 to 2018, systemic therapy with Valsartan $160 \mathrm{mg} /$ hydrochlorothiazide $25 \mathrm{mg}$, at times replaced for short periods with Valsartan $160 \mathrm{mg}$ (from the same company), once daily. In 2018, valsartan monotherapy was replaced till 9/2020 with valsartan $160 \mathrm{mg}$ / hydrochlorothiazide $12.5 \mathrm{mg}$ once daily (by another pharmaceutical company) (fig 2b, 2c). Bisoprolol $5 \mathrm{mg}$ - one half a day and Amlodipine $5 \mathrm{mg}$ once daily. Due to suspicion (clinical) of reactivation of a disease known in 2018 in the area of the upper extremities - Kaposi's sarcoma, the patient is presented in the dermatological clinic in order to clarify the severity of the lesions and introduce possible 

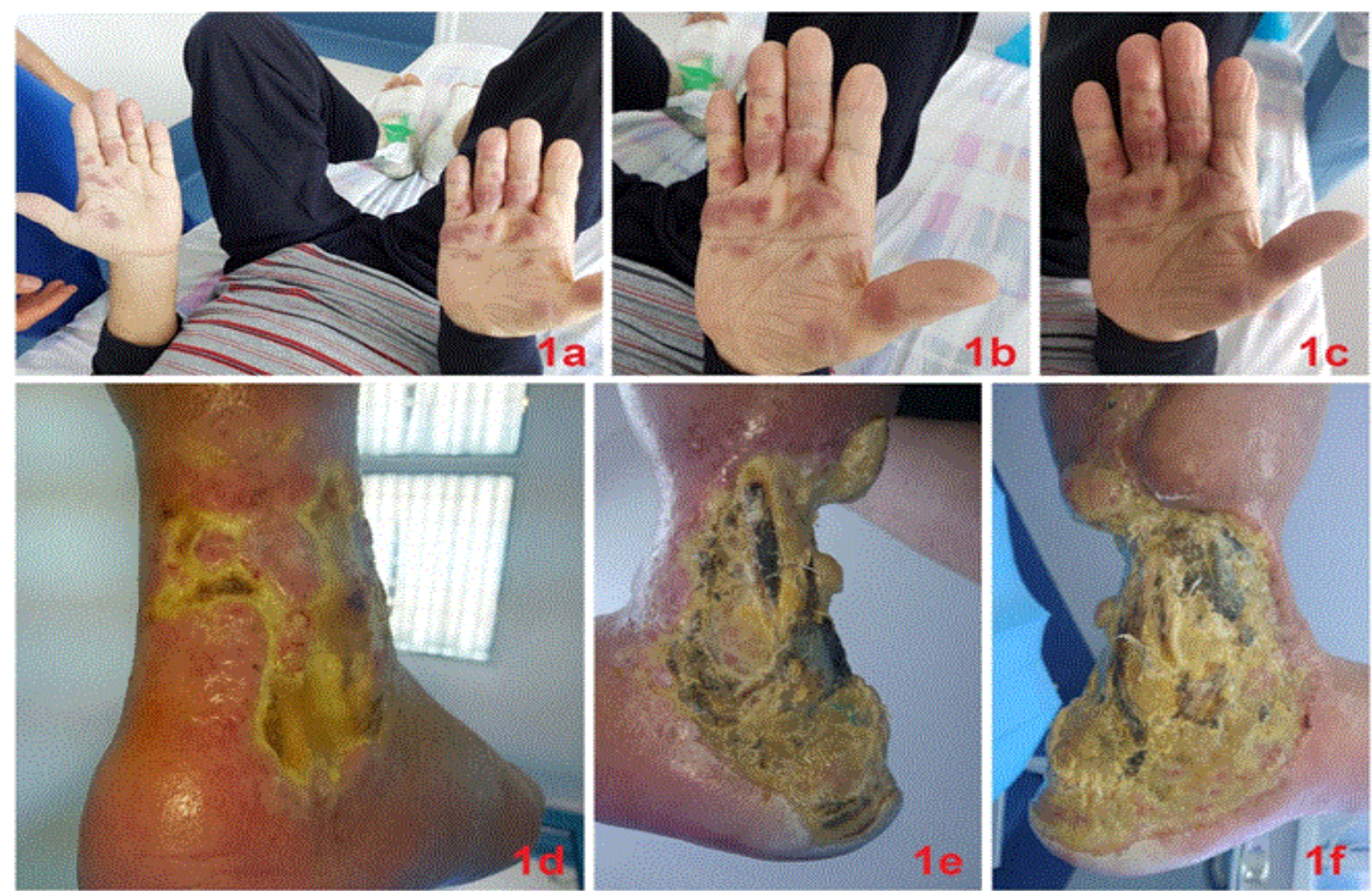

Figs 1a), 1b), 1c): Patient on systemic antihypertensive therapy with valsartan / hydrochlorothiazide and subsequently proved co-development of 3 tumors in 2018: Kaposi's sarcoma, skin melanoma and colon cancer. Currently suspected of reactivating Kaposi's sarcoma in the upper extremities. Clinically macular, plaque-like rash with mild pain on touch, symmetrical location of the lesions

Figs 1d), 1e), 1f): Patient with a history of Kaposi's sarcoma and radiotherapy. Condition after necrectomy and surgical debridement (under general anesthesia) of necrotic tissue localized in the area of the distal parts of the lower legs, dorso / ventral, symmetrical location of the affected areas
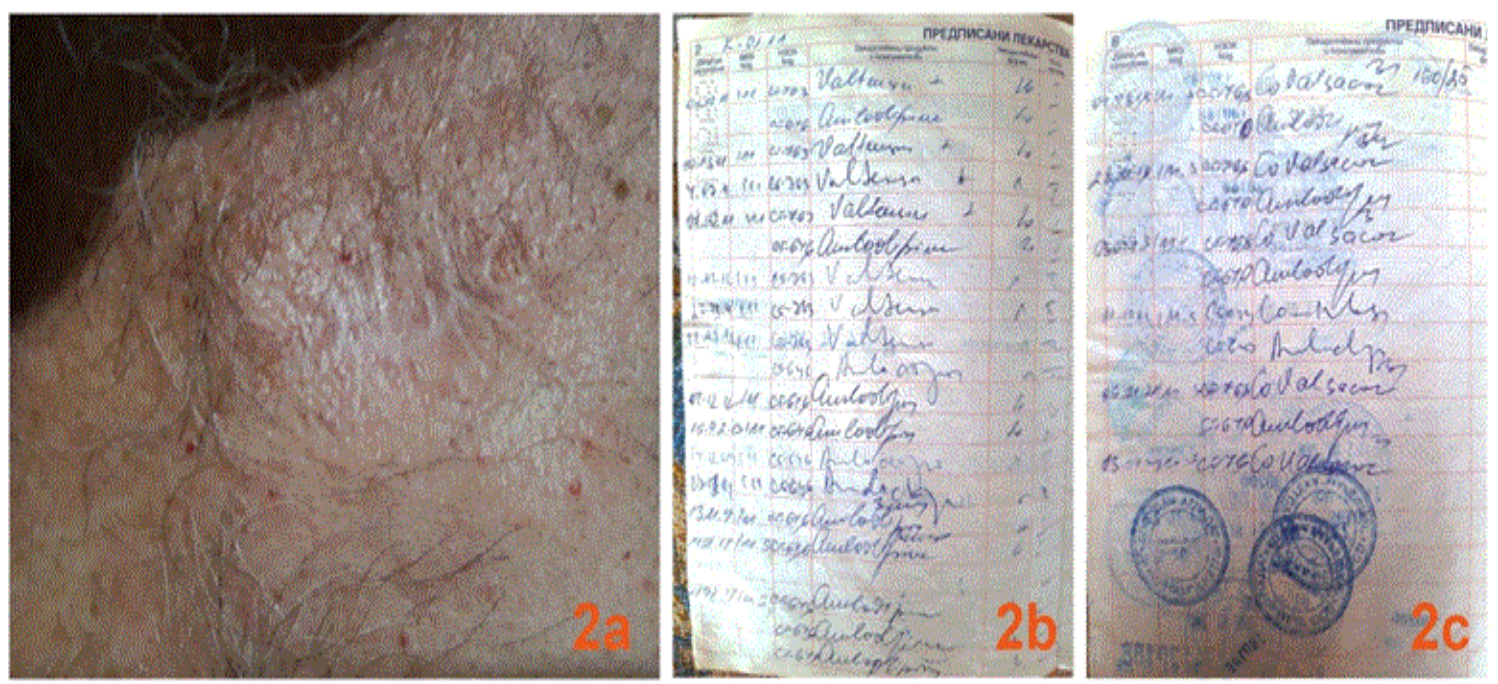

Figure 2a: Postoperative cicatrix in the region of the supraclavicular sinistra region in a patient with drug-induced thin skin melanoma after treatment of hypertension with valsartan / hydrochlorothiazide.

Figure 2b), 2c): Original patient prescription book.

Citation: Tchernev G, Poterov G (2020) Drug Induced Cancers: Simultaneously Development of Cutaneous Melanoma, Colon Carcinoma and Kaposi Sarcoma under Valsartan/ Hydrochlorothiazide. Clin Res Dermatol Open Access 7(5): 1-8. DOI: 10.15226/2378- 
treatment (Fig. 1a, 1b, 1c). In addition, there are complaints in the form of severe pain in the lower extremities due to non-healing deep necrotic wounds that occurred within post-radiation radiodermatitis and subsequent necrectomy in the recent past (Fig. 1d, 1e, 1f). According to data from the anamnesis and the available documentation - in 2018 the patient has clinical and dermatoscopical data for superficial melanoma in the area of regio supraclavicularis sinistra (fig. 2a). In May 2018, a surgical excision was performed with a primary resection field of $2 \mathrm{~cm}$ in all directions (in a plastic and reconstructive surgery clinic), and the subsequent histopathological verification showed evidence of thin skin melanoma (Figure 2a). Histology shows evidence of epidermis and dermis with infiltration of a superficial type of malignant melanoma with a maximum size (tumor size after fixation) of $18 \mathrm{~mm}$. No ulceration data, $0.5 \mathrm{~mm}$ Breslow tumor thickness. Clark III, mild peri- and intratumoral infiltrate, without lymphovascular and perineural invasion. No mitotic figures, no regression zones, stage (pT1bN0M0). Immunohistochemistry: Melan A and HMB-positive reaction, Ki-67-moderate proliferative activity in the papillary dermis. Referred for observation at the regional Oncology dispensary and without data on the progression of the disease at the moment 2020 year.

At the same time, in 2018, the patient had a second simultaneously developing skin tumor on the dorsal surface of the feet, symmetrically, bilaterally. The skin biopsy taken in April 2018 shows data for: compact orthohyperkeratosis, papillomatosis, moderate acanthosis with hypermelanosis of the lower epidermal segment, fibrous subepidermal plate, compact proliferation of fusiform and epithelioid oocyte endothelial cells, endothelial endothelial cells, melanophage-rich stroma, with a promoter phenomenon, intact eccrine sweat glands at the dermahypodermis border, where foci of endothelial proliferation enter. The histological picture corresponds to Kaposi's nodular sarcoma. The performed indirect immunofluorescence for HHV-8 IgG - 1: 200 titer, at a rate of: 1: 100. HIV: negative serology. On the occasion of the diagnosis, the patient was admitted to a radiotherapy clinic in 2018, to conducting deep X-ray therapy. A total of 3 courses of X-ray therapy were conducted. During the first two courses (March and September 2018) with an initial dose of 7 Gy, then up to $28 \mathrm{~Gy}$. In the third cycle, in October / November 2018, the dose was increased from up to $35 \mathrm{~Gy}$. There is a good clinical response. A year later, at the end of 2019, there was a deterioration of the local finding in the field of radiotherapy. In 2020, a repeat biopsy was taken to rule out a recurrence of Kaposi's sarcoma. There is no histopathological evidence of recurrence of Kaposi's sarcoma, and the histological picture corresponds to post-radiation chronic dermatitis. He entered the plastic and reconstructive surgery clinic for hydrotherapy and aseptic treatment of the areas affected by the radiotherapy. Debridement, excision and curettage of the devitalized tissues to a seemingly healthy, vital basis were performed. A dressing with nanocrystalline silver was performed. The histopathological finding is again with data for: skin with hyperplasia, acanthosis and hyperkeratosis of the epithelium, as well as with subdivident fibrosis and hyalinosis. No evidence of tumor cells. The recommendations are for intensive local and, if necessary, systemic antibiotic therapy according to the results of the microbiological examination and the antibiogram.

In parallel, in July 2018, as part of a PET scan, focally increased metabolic activity was visualized in the wall of a transverse colon, with an SUV max. 3.7, interpreted as a possible benign polyp. The recommendations are to clarify the dignity of the lesion by performing fibro-colonoscopy and biopsy. The patient refuses to have a colonoscopy and biopsy for a period of about 1.5-2 years. It was not until $7 / 2020$ that the patient's condition deteriorated and urgent hospitalization was required due to stomach pain accompanied by nausea and vomiting of hematin substances. In the context of hospitalization and follow-up, evidence of transverse colon adenocarcinoma was established. Resection of the colon and locoregional lymph nodes was performed. Histological data are for adenocarcinoma of the colon, with no evidence of regional lymph node metastases.

The PET SCAN performed postoperatively in 8/2020 showed evidence of hepatic hematogenous dissemination, subsequently histopathologically verified by liver biopsy, as metastases from adenocarcinoma of the colon. The patient was referred for planning chemotherapy at the medical oncology clinic.

\section{Discussion}

The systemic therapy with antihypertensive drugs such as sartans and thiazide diuretics is likely to become a "systemic", but modestly increased risk of recurrence of a type of "modest" but at the same time, according to other authors, somewhat "substantial-risk" for oncological disease [1, 5-7].

\subsection{How Sartans cause Cancer? Consequences for the patients.}

If we stop and analyze in detail this kind of "nonsense combination" of antihypertensive drugs, it would be appropriate to start with Sartans, because even their name turns out to be enigmatic. The name comes from the Arabic language: Namely, that "Sartan" means "Cancer". It remains unclear whether our ancestors put any intent into this definition, but they seem to have invested at least some wisdom. In practice, sartan therapy has two main "modestly increased risks":

1) The "modest increased risk" of a "pure substance" that has proven its potential carcinogenic effect, both in vitro [9-10], and in vivo $[3,7,11]$ which patients should not worry about, despite that single or multiple melanomas may occur e.g. [12].

2) The second "modest increased risk" arises from the FDA / EMA's information that up to 3 nitrosamines are available, causing (again according to official information from the control authorities) up to 11 forms of cancer [3]. In practice, however, patients should not worry, as the advice of control authorities around the world is: "Don't worry. Ask your cardiologist! Keep taking your medication! ... or translated into even more understandable language: "The risk is negligible! Only 11 forms of cancer are there after all?

Or in practice, your cardiologist should mention the following: "Due to the modest, partly scientifically based (from high-quality medical publications), but at the same time negligible increased risk of being affected by 1 to 13 cancers, you can safely take your 


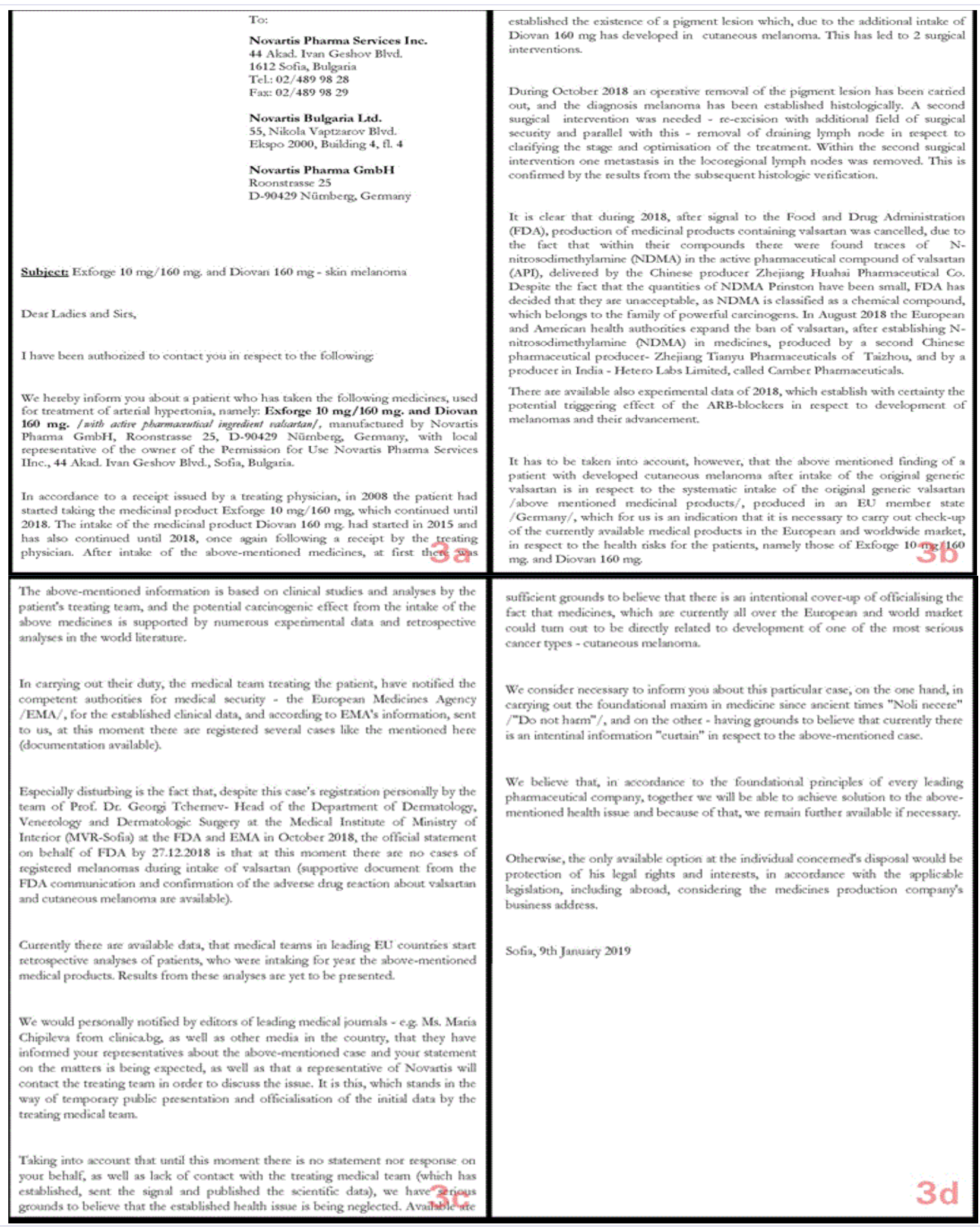

Figures 3a-d): Official address from 2019 to Novartis regarding its refusal to comment on the two drugs in question, which are already described (and then) in the world literature as the first serious adverse drug reaction in the form of cutaneous melanoma. There is no answer and explanation why the company has communicated with online health platforms, radio and television, and according to data, they have been warned not to comment on our already official scientific data. 2 years from now - in 2018, until now: The balance is the observation and registration of new and new cancers that have occurred both after starting monotherapy with sartans and after starting combination therapy with sartans with hydrochlorothiazide. 


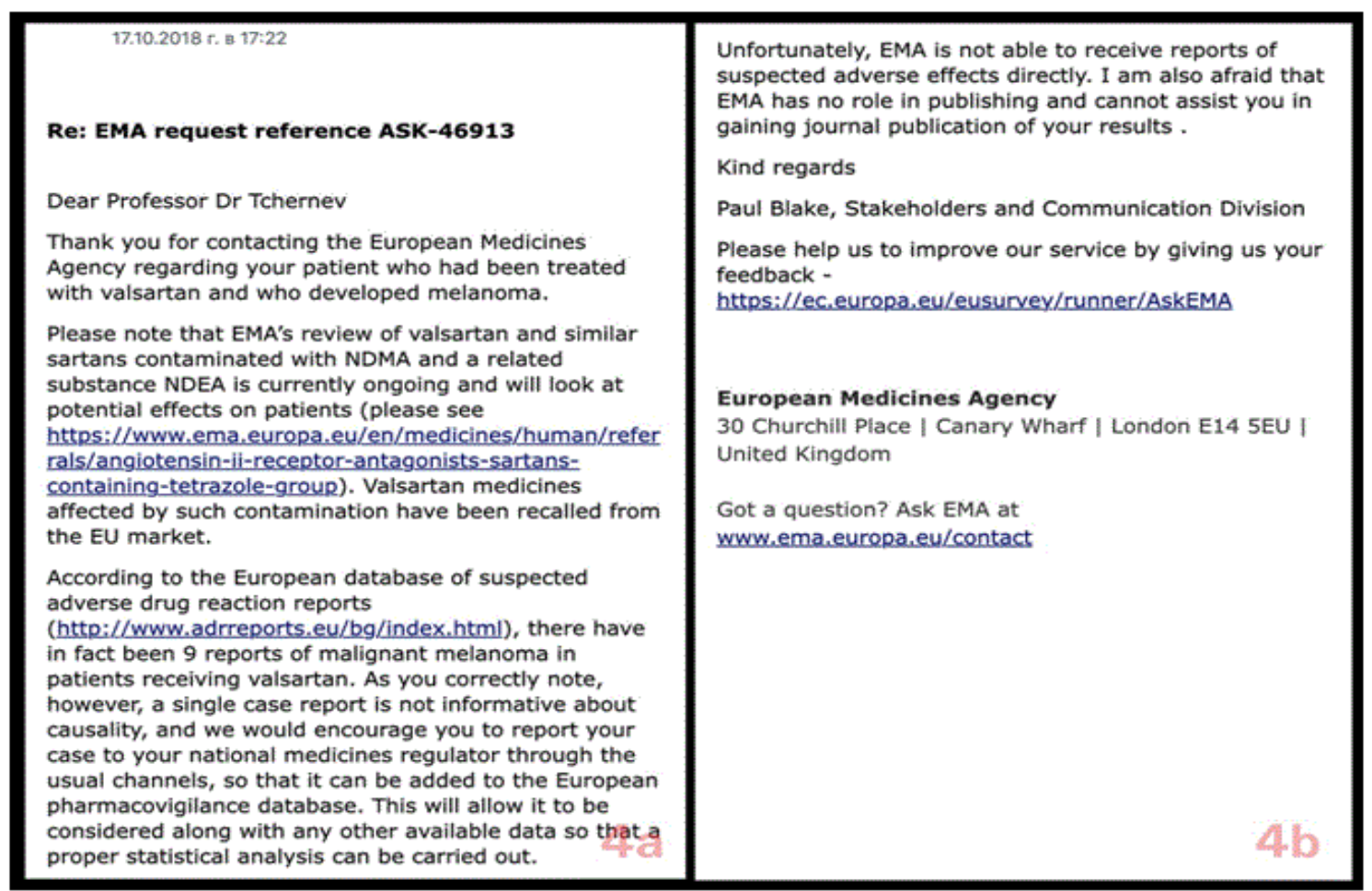

Figure 4a, 4b: The official response of the EMA, which is in full confirmation and at the same time in complete contrast to the data shared by our Ministry of Health in 2020, to the Bulgarian press. The answer EMA informs about already available 9 melanomas in 2018 after using only one preparation from the group of sartans - valsartan. And the response of the Ministry of Health in 2020 to actualno.com, postulated that after an official inquiry to the EMA, there is not a single case of melanoma registered after the start or within the use of valsartan. After adding only our new cases from Bulgaria, neglected by BDA, this number should certainly be over 25 .

medicine from the group of sartans. Don't worry [12]!”

Unfortunately, however, a number of patients do not come to the question of "your cardiologist", but rather to the question of the nearby "modest" or "essentially modest" regional oncologist in all probability. However, it is unclear whether he is "risky" or just "modest"? However, according to the FDA, it could probably be "modestly risky."

Summarizing the data, it could be concluded that according to official information from the FDA bulletin, sartans should be taken without worries, although 1) scientific in vivo and in vitro data, and 2) data from control authorities worldwide in the face of the FDA / EMA, refer to: The possible occurrence or "negligibly modestly increased risk" of developing a total of around or at the time of exactly 13 "negligibly modest" cancers $[1,3,7,9,10-12]$.

There is no doubt that healthcare professionals do not have the question or dilemma of whether patients will be affected by the "pure substance" or any of the available nitrosamines ... because in practice it turns out that they (the patients) have probably minimal chances in both cases? The "modest chance" that they will not be affected is also there! As well as the modest chance - will they survive later? But in all likelihood there is a risk of survival, but precisely because of the fact that the risk of being affected is "rather modest."

The Connections: FDA, EMA and the Pharmaceutical Industry.
Another important question and great concern about the issue of antihypertensive medication with sartans arises from the additional data of the control authorities in the face of the EMA and FDA again: "Companies should self-test within 6 months and inform whether their medications contain nitrosamines, which cause up to 11 cancers." Apparently, the FDA / EMA's expectations of some of the heavy multibillion-dollar pharmaceutical companies to announce that their drugs contain carcinogens are indeed very bold, daring and probably filled with a lot of love and pre-Christmas friendly mood. In practice, this would mean that companies would 'expose themselves' to potential or hundreds to thousands of patients' claims, starting at $\$ 2$ million to $\$ 1$ billion per single claim [13]. Equivalent to bankruptcy or "public suicide." Till now, there is no pharmaceutical company on the market that has announced that it has found 1 or three carcinogens in its preparations. The information still remains confidential.

There are companies in the pharmaceutical market that repeatedly and silently pay fines imposed by a US federal court in the range of $\$ 678$ million for 2020 and [14], as well as $\$ 370$ million in 2015 [15], even refusing public comment on the subject for their crimes over the years:

\section{1) THE GUARDIAN}

"There were fishing junkets, golf outings and round-table events at Hooters. And then there were the six-figure honorariums that 
the Novartis Pharmaceutical Corp. paid to several doctors who wrote thousands of prescriptions for cardiovascular and diabetes drugs the company made.

Now, after admitting it used an extensive kickback program for nearly a decade to influence doctors to prescribe certain medications, Novartis will pay $\$ 678$ million to settle a fraud lawsuit, federal prosecutors in New York announced on Wednesday.

Most of the drugs prescribed by the doctors who received kickbacks have been used to treat high blood pressure and include Lotrel, Diovan, Exforge, Tekturna, Valturna and Tekamlo, according to the settlement. The doctors who received the kickbacks also prescribed Starlix, which is used to treat Type 2 diabetes [14]. "

\section{2) UNITED STATES DEPARTMENT OF JUSTICE}

U.S. Attorneys » Southern District of New York » News » Press Releases, 20.11,2015

"Manhattan U.S. Attorney Announces \$370 Million Civil Fraud Settlement Against Novartis Pharmaceuticals For Kickback Scheme Involving High-Priced Prescription Drugs, Along With $\$ 20$ Million Forfeiture Of Proceeds From The Scheme [15]. "

The main reason for the company NOVARTIS to be mentioned and themed in our publication and in this case is that 1) the reason for the development and description of the first case in the world literature of drug-induced cutaneous melanoma (metastatic) in 2018 is due to the use of two sartans of the company NOVARTIS [3].

As it should be noted, our repeated official addresses and desire for debates on the topic were directly or indirectly hindered again by the company NOVARTIS (Figure 3a, 3b, 3c, 3d). Moreover, our team was repeatedly warned that the company does not want and does not want to talk about the topic, as the media / platforms (which informed us about the problem or the inability to give publicity) would give publicity to the problem only after the NOVARTIS company's consent?

The question remains: Who should be responsible for the melanomas that have arisen during these 2 years from Novartis' anti-hypertensive drugs? Are we referring to melanomas that have arisen after the neglect of this issue by the company and the control bodies at the regional level for the period from 2018?

They refer in this case to metastatic type of melanomas $[3,12]$, which probably arose due to the active substance $[9,10]$ and not to the presence of nitrosamines. We are referring to this detail, because in its response, the company skillfully shifts the blame for generating cancer to carcinogenic impurities, and does not directly answer the question of the potential carcinogenic effect of the pure substance. In practice, it refuses direct and official debate.

A number of experimental scientific data in the last 2 years support the thesis that the pure substance of sartans could potentiate metastasis in melanomas $[9,10]$. The individual receptor status of the patients in these cases is decisive $[9,10]$.

Thiazides as additional drug related cancer risk: The multiCancer development. The Hidden Data.

Regarding the "drug-induced modest-risk cancers", some clarity has been introduced [1]. Because of this fact, we should pay attention to some defined in the literature as drug-induced "substatially-risk cancers", which include also melanoma, which occurred after the use of thiazide diuretics, e.g. (4-6.8).

In practice, it turns out that the combination of (according to a number of authors) the "modestly risky" (for melanoma) drug (Valsartan) [1] with the "substantially risky" (again for melanoma) (hydrochlorothiazide) [8], in a Bulgarian patient, proved once again or again "quite risky" in terms of the development and manifestation of cutaneous melanoma, but in combination with two other tumors: Kaposi's sarcoma and colon cancer. And such a similar drug combination (sartan / hydrochlorothiazide) leading to cutaneous melanoma or melanoma / other tumors is actually observed $[6,7]$.

The combination of valsartan and hydrochlorothiazide could lead to the development of prostate cancer and melanoma in the same patient [6], and in the first patient described in the literature with Irbesartan-induced cutaneous melanoma, sartan was combined also with hydrochlorothiazide [7].

It is unclear at this time whether an investigation has been carried out and what the results are with the valsartan monopreparation / Valsartan / Hydrochlorothiazide combination preparation reported by us to the Executive Agency for Medicinal Products for the absence or presence of nitrosamines. Such data have not been received for a period of 2 years. The data from this inspection are not available at the moment, but drug-induced oncological diseases remain a daily problem and an indisputable fact. Regardless these data, there are experimental ones that prove the procarcinogenic effect of the pure substance, whether or not they contain nitrosamines $[9,10]$.

In a number of European countries, but also in America, the manifestation of intestinal neoplasms (colon cancer) is perceived as a serious side effect of nitrosamines contained in sartans. The eventual result of recognizing the truth of these facts (checking for the presence of nitrosamines in the preparations) would undoubtedly lead to an attack on pharmaceutical companies with multimillion-dollar claims. This would explain, at least hypothetically, the huge manipulations and attempts to cover up the currently registered tumors in certain regions not only in the Balkans, but also around the world. The data is intentionally concealed.

We are providing the original correspondence with the EMA regarding the report on valsartan and melanoma to the EMA from 2018, which shows that at that time there were 9 melanomas registered after taking a single drug from the group of sartans valsartan (Fig. 4a , 4b). We look forward to the response of the former Minister of Health and the current Minister of Finance in our country regarding this spectacular manipulation and concealment of data for a period of 2 years, for the solution of 
which the required legal international responsibility will soon be required.

For the first time in the world literature, a patient with the simultaneous development of three cancers after the introduction of treatment with Valsartan and Hydrochlorothiazide is presented: cutaneous melanoma, Kaposi's sarcoma and colon cancer. An analysis of the available information is being made, which could lead to the idea that drug-mediated carcinogenesis is not a myth, but rather a reality.

The scientific basis for our analysis is strongly confirmed by the scientific data available in the last 10 years in the most renowned medical journals $[1,4,5,8,9,10]$.

\section{References}

1. Sipahi I, Debanne SM, Rowland DY, Simon DI, Fang JC. Angiotensinreceptor blockade and risk of cancer: meta-analysis of randomised controlled trials. Lancet Oncol. 2010;11(7):627-636. doi: 10.1016/ S1470-2045(10)70106-6.

2. McCarthy M. FDA officials disagree on safety of angiotensin receptor blockers. BMJ. 2013;346:f3730. doi: 10.1136/bmj.f3730.

3. Tchernev G, Temelkova I. Valsartan Induced Melanoma?! First Description in Medical Literature! Open Access Maced J Med Sci. 2018;6(12):2378-2380.

4. Pedersen SA, Gaist D, Schmidt SAJ, Hölmich LR, Friis S, Pottegård A. Hydrochlorothiazide use and risk of nonmelanoma skin cancer: A nationwide case-control study from Denmark. J Am Acad Dermatol. 2018;78(4):673-681.

5.Schmutz JL. L’hydrochlorothiazide augmenterait le risque de mélanome [Hydrochlorothiazide appears to increase risk of melanoma]. Ann Dermatol Venereol. 2018;145(10):643-644.

6. Tchernev G, Temelkova I. Valsartan/hydrochlorothiazide induced prostate carcinoma in a patient who subsequently developed melanoma. J Biol Regul Homeost Agents. 2019;33(4):1125-1127.
7. Tchernev G, Temelkova I. Drug-Induced Melanoma: Irbesartan Induced Cutaneous Melanoma! First Description in the World Literature! Open Access Maced J Med Sci. 2019;7(1):114-116.

8. Pottegård A, Pedersen SA, Schmidt SAJ, Hölmich LR, Friis S, Gaist D. Association of Hydrochlorothiazide Use and Risk of Malignant Melanoma. JAMA Intern Med. 2018;178(8):1120-1122.

9. Olschewski DN, Hofschröer V, Nielsen N, Seidler DG, Schwab A, Stock C. The Angiotensin II Type 1 Receptor Antagonist Losartan Affects NHE1-Dependent Melanoma Cell Behavior. Cell Physiol Biochem. 2018;45(6):2560-2576.

10. Renziehausen A, Wang H, Rao B, Weir L, Nigro CL, et al. The renin angiotensin system (RAS) mediates bifunctional growth regulation in melanoma and is a novel target for therapeutic intervention. Oncogene. 2019;38(13):2320-2336.

11. Tchernev G, Temelkova I. Irbesartan Induced Cutaneous Melanoma! Second Case in the Medical Literature! Open Access Maced J Med Sci. 2019;7(1):121-123.

12. Tchernev G, Poterov G, Malev V. Sartans and Melanoma: Valsartan Induced Multiple Primary Cutaneous Melanomas: first Description in the Medical Literature! Clin Res Dermatol Open Access. 2020;7(4):1-3.

13. THE GUARDIAN: Monsanto must pay couple $\$ 2$ bn in largest verdict yet over cancer claims. Sam Levin. 2019.

14.THE NEW YORK TIMES: It Paid Doctors Kickbacks. Now, Novartis Will Pay a $\$ 678$ Million Settlement. Neil Vigdor. 2020 .

15. UNITED STATES DEPARTMENT OF JUSTICE, U.S. Attorneys » Southern District of New York » News » Press Releases. 2015

16. Tchernev G, Temelkova I. Olmesartan/valsartan induced giant achromatic cutaneous melanoma: "modified“ one-step surgical approach with favourable outcome. J Biol Regul Homeost Agents. 2019;33(6):1775-1777. 